\title{
Conductivity prediction of proppant-packs based on particle size distribution under variable stress conditions
}

\author{
Tiancheng Liang ${ }^{1, *}$, Jinwei Zhang ${ }^{2}$, Chuanyou Meng ${ }^{1}$, Nailing Xiu ${ }^{1}$, Bo Cai ${ }^{1}$ and Haifeng Fu ${ }^{1}$ \\ ${ }^{1}$ Petrochina Research Institute of Petroleum Exploration and Development, Beijing, China \\ ${ }^{2}$ Shandong University of Science and Technology, Qingdao, China
}

\begin{abstract}
The conductivity of the proppant-packs is critical in the productivity of hydraulically fractured wells. Proppants are also the best medium for studying particle packing. Sand and ceramic media are two most common proppants used for hydraulic fracturing. This study focuses on investigate the relation between conductivity and properties of proppant-packs, the particle-size distribution, porosity and mean particle diameter have been measured. The porosity of the proppant pack under zero pressure is determined from bulk density and apparent density. To accurately measure the porosity under variable closed stress conditions, the compressed width was taken into consideration. The particle size distribution was measured from sieve analysis. The paper presents results obtained by conducting routine conductivity test on a variety of proppants. The conductivity-porosity relationships are nonlinear. The conductivity is most sensitive to mean grain size, followed by closed stress, and then sorting. Larger median diameter always correlates to higher conductivity at low stress. Loss of conductivity with stress is more severe for large particles sands than small particles. The binomial method can be used to calculate the conductivity of different types and mesh proppants, which is shown to fit conductivity-mean diameter data successfully. The research is of guiding significance to choose the proper size distribution proppants in hydraulic fracturing. Meanwhile, the binomial method is a better predictor of proppant-packs conductivity based on particle size distribution.
\end{abstract}

\section{Introduction}

Hydraulic fracturing is one of the important techniques to increase single well production and increase recovery in the low permeability oil and gas field. The purpose of hydraulic fracturing is to form a highly conductive channel connecting the reservoir formation with the wellbore ${ }^{[1]}$. The proppant enters the new hydraulic fractures of the rock formation with the high-pressure fracturing fluid, it plays an important role in supporting the hydraulic fractures not to be closed when pumping stopped. The proppant-packs maintain high conductivity and allow oil and gas to flow. Therefore, the conductivity of proppant-packs is directly related to the fracturing construction quality and stimulation effect.

Sand and ceramic are the two most commonly proppants used for hydraulic fracturing. In 2018, Petrochina used 1.82 million tons of sand and 1.1 million tons of ceramic. In reservoirs with a depth of more than 1500 meters, ceramic proppants were mainly used. Proppant selection deeply affects the physical success and economic optimization of hydraulic fracturing. Proppant conductivity should be the most important indicator and also the most concerned parameter for oil and gas companies ${ }^{[2,3]}$. However, the biggest challenge may become simply locating sufficient quantities of proppant, with the driving factors often simplified to size distribution and crush resistance. It is crucial to establish the relationship between the basic properties and the conductivity of proppant ${ }^{[4-6]}$.

This study focuses on investigate the relation between conductivity and properties of proppant-packs, the particle-size distribution, porosity and mean particle diameter have been measured. The porosity of the proppant pack is determined from bulk density and apparent density. To accurately measure the porosity under variable closed stress conditions, the compressed width was taken into consideration. The particle size distribution was measured from sieve analysis. Based on the laboratory study on the short-term conductivity of proppant with different type, density, particle size distribution and crush resistance rate, the main factors affecting the conductivity of fracturing proppant are identified.

\section{Experimental procedure}

\subsection{Test samples}

Laboratory measurements of proppant basic performance and conductivity have been performed through hundreds of tests. The experimental samples are all proppants tested in our laboratory from 2010 to 2018 , including sand and ceramic samples. There are mainly 20/40 mesh, $30 / 50$ mesh, 40/70 mesh and 70/140 mesh in the particle

\footnotetext{
* Corresponding author: liangtc69@petrochina.com.cn
} 
size. The samples came from proppant manufacturers across the country and the hydraulic fracturing construction sites of PetroChina oilfield.

\subsection{Experiment equipment}

The main equipments of the conductivity experiment include hydraulic load frame, pack width measurement device, standard test unit, test fluid drive system, pressure indicators, etc., all configured in accordance with the requirements in the standard API RP 61.

The apparatus of the loose pack bulk density, apparent density and sieve analysis of proppants are configured according to standard ISO 13503-2.

\subsection{Experimental method}

The conductivity testing is based on the standard API RP 61 recommended method for evaluating short-term proppant pack conductivity under laboratory conditions. The test unit is a linear flow design with a bottom area of $64.5 \mathrm{~cm}^{2}$. The concentration of proppants loading the test cell is $5 \mathrm{~kg} / \mathrm{m}^{2}$, the hydraulic pressure is applied to the test unit, using a loading rate of $3500 \mathrm{kPa} / \mathrm{min}$. The closure pressure is $10 \mathrm{MPa}, 20 \mathrm{MPa}, 30 \mathrm{MPa}, 40 \mathrm{MPa}$, $50 \mathrm{MPa}, 60 \mathrm{MPa}$, the closing pressure of 6 different levels is gradually increased, and the pressure is stabilized at each closing pressure for $10 \mathrm{~min}$. When the liquid flows through the proppant pack layer under different closing pressure, the width of proppant pack, pressure difference and flow rate are measured. Constant-flow-rate pumps are tested at 2-3-4 $\mathrm{ml} / \mathrm{min}$. According to Darcy formula, the conductivity and the permeability of proppant pack layer are calculated under laminar flow condition ${ }^{[7]}$.

$$
\mathrm{KW}_{f}=\frac{5.555 Q \mu}{\Delta P}
$$

Where , $\mathrm{K} W_{f}$ is the proppant pack conductivity, expressed in micron square centimeter $\left(\mu m^{2} . \mathrm{cm}\right) ; \mathrm{W}_{\mathrm{f}}$ is the the proppant pack thickness, expressed in centimeter $(\mathrm{cm}) ; \mathrm{K}$ is the proppant pack permeability, expressed in micron square $\left(\mu m^{2}\right) ; \mu$ is the test liquid viscosity at test temperature, expressed in millipascals second (mPa.s); Q is the flow rate, expressed in cubic centimeters per minute $\left(\mathrm{cm}^{3} / \mathrm{min}\right) ; \Delta P$ is the pressure drop (pressure upstream minus pressure downstream), expressed in kilopascals $(\mathrm{kPa})$.

Porosity can be calculated from bulk density and apparent density. After the closure stress is applied, the proppant will be compacted, and the width of the proppant pack layer will become smaller. In the experiment, the width can be measured, and the bulk density of the proppant under different pressures can be calculated. Apparent density is a constant value for each proppant. The bulk density is calculated according to standard ISO 13503-2. Equations (2) to (3) shall be used to calculate the porosity for different closed stress:

$$
\begin{aligned}
\rho_{v} & =\frac{32.26}{64.52 * W_{f}} \\
\phi & =1-\frac{\rho_{v}}{\rho_{a}}
\end{aligned}
$$

Where, $\mathrm{W}_{\mathrm{f}}$ is the the proppant pack thickness, expressed in centimeter $(\mathrm{cm}) ; \rho_{v}$ is the bulk density, expressed in in grams per cubic centimeter $\left(\mathrm{g} / \mathrm{cm}^{3}\right) ; \rho_{a}$ is the apparent density, expressed in grams per cubic centimeter $\left(\mathrm{g} / \mathrm{cm}^{3}\right)$; $\$$ is the Porosity, expressed in decimal.

\section{Experimental result}

\subsection{Mean diameter and conductivity analysis}

The products of the same specification, such as the products of the same 20/40 mesh specification, have different particle size distributions, so the larger the mean diameter, the greater the conductivity, and the particle size distribution can greatly affect the conductivity. The approximate conductivity can be obtained based on the relationship between the mean diameter and the conductivity. As the closed pressure increases, the proppant's conductivity decreases, and the larger the particle size, the more the conductivity decreases. Ceramic and sand have different declines in conductivity, and the conductivity of sand is more sensitive to the closed stress. When the closed pressure is loaded to $40 \mathrm{MPa}$, the conductivity of sand is greatly reduced. The conductivity of ceramic is 5 times that of sand. The larger the proppant particle size, the larger the difference in conductivity. When the closed pressure is applied to $60 \mathrm{MPa}$, the conductivity of ceramic is 10 times that of sand. There is more scatter in this sand data with the pressure at $60 \mathrm{MPa}$, so it is not to keep the same trendline form. Large proppant size can improve the fracture conductivity significantly, but at the same time brings a challenge for the proppant transport.

A binomial method was used to fit the relationship between the mean diameter and the conductivity. The fitting formula show below:

$$
\mathrm{P}=\mathrm{a} x^{2}+b x+c
$$

Table 1. Fitting coefficient of the mean diameter and the conductivity in ceramic.

\begin{tabular}{|c|c|c|c|c|c|c|}
\hline \multirow{2}{*}{$\begin{array}{c}\text { Closed } \\
\text { stress }\end{array}$} & \multicolumn{3}{|c|}{ Ceramic } & \multicolumn{3}{c|}{ Sand } \\
\cline { 2 - 7 } & $\mathrm{a}$ & $\mathrm{b}$ & $\mathrm{c}$ & $\mathrm{a}$ & $\mathrm{b}$ & $\mathrm{c}$ \\
\hline $10 \mathrm{MPa}$ & 0.0004 & -0.065 & 13.2898 & 0.0000 & 0.1316 & -15.50 \\
\hline $20 \mathrm{MPa}$ & 0.0003 & -0.026 & 5.7839 & 0.0000 & 0.0718 & -7.430 \\
\hline $30 \mathrm{MPa}$ & 0.0003 & -0.019 & 4.0859 & 0.0000 & 0.0240 & -0.615 \\
\hline $40 \mathrm{MPa}$ & 0.0002 & 0.0033 & 0.4506 & 0.0000 & 0.0038 & 2.1275 \\
\hline $50 \mathrm{MPa}$ & 0.0001 & 0.0176 & -1.7067 & 0.0000 & 0.0103 & -0.911 \\
\hline $60 \mathrm{MPa}$ & 0.0001 & 0.0279 & -3.3650 & 0.0000 & 0.0083 & -0.650 \\
\hline
\end{tabular}



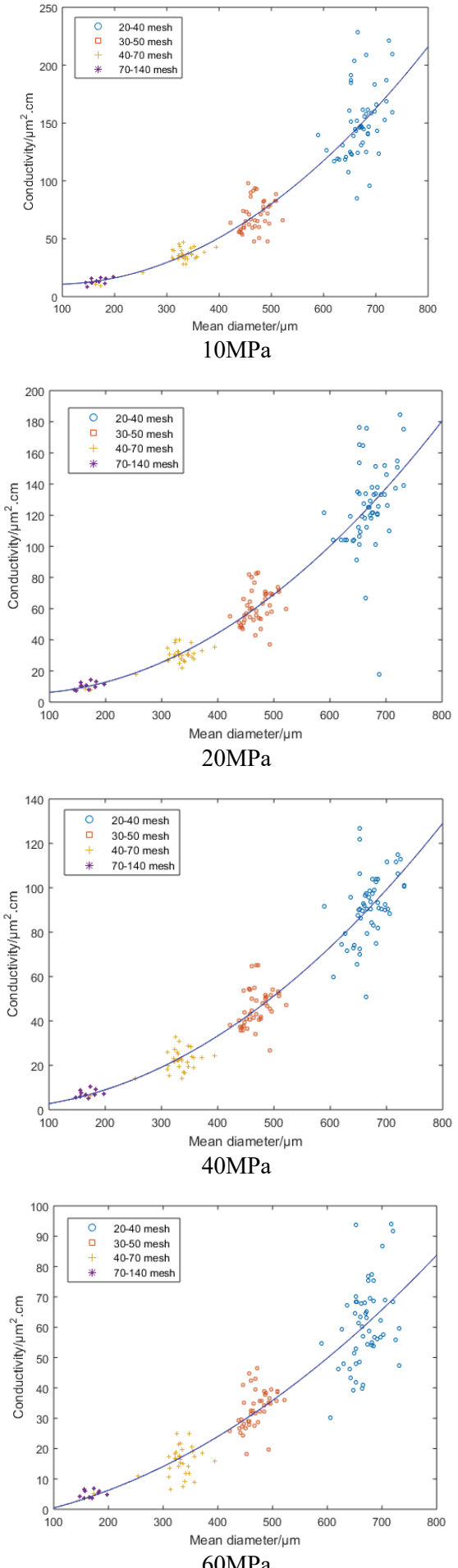

Fig.1. Relationship between mean diameter and conductivity in ceramic.
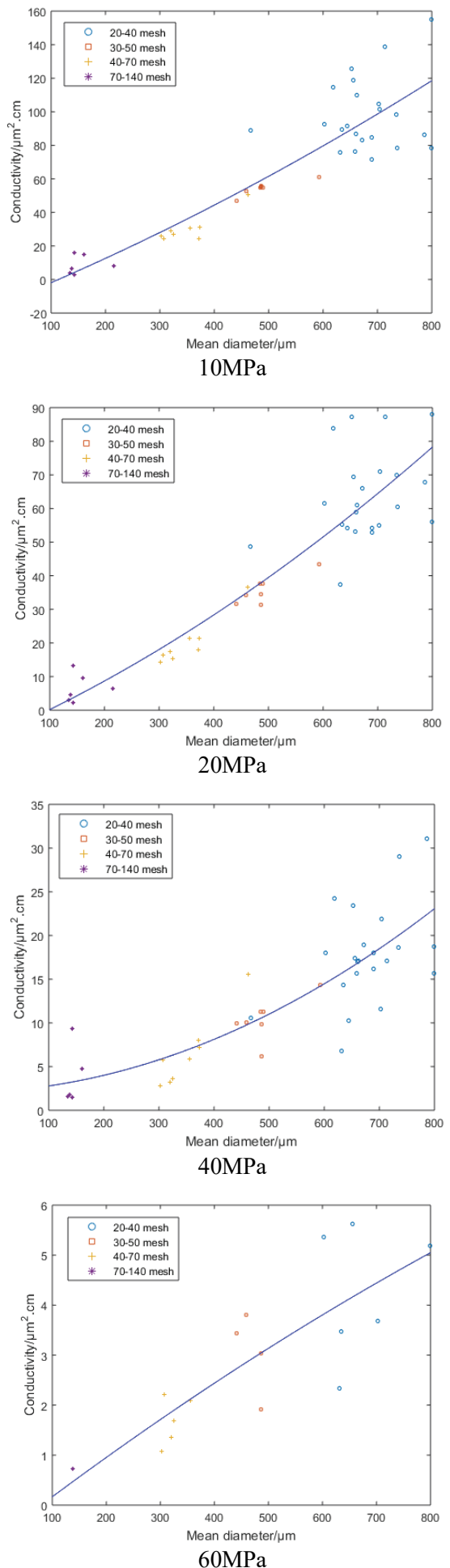

Fig.2. Relationship between mean diameter and conductivity in sand.

\subsection{Mean diameter and Porosity analysis}

Figure 3 and 4 show the porosity of proppants over a range of confining pressures. As we expect, by increasing the confining pressure the porosity of samples decreases. We also can see that the porosity of large 
particles sample is lower in comparison with small particles proppant packs. The $\mathrm{min} / \mathrm{max}$ porosity of ceramic is about $45 \%$ to $55 \%$ under $10 \mathrm{MPa}$ and about $40 \%$ to $50 \%$ under $60 \mathrm{MPa}$. The $\mathrm{min} / \mathrm{max}$ porosity of sand is about $40 \%$ to $45 \%$ under $10 \mathrm{MPa}$, and about $34 \%$ to $37 \%$ under $60 \mathrm{MPa}$. Compared with ceramic, the porosity of sand decreases faster with the increase of closed pressure.
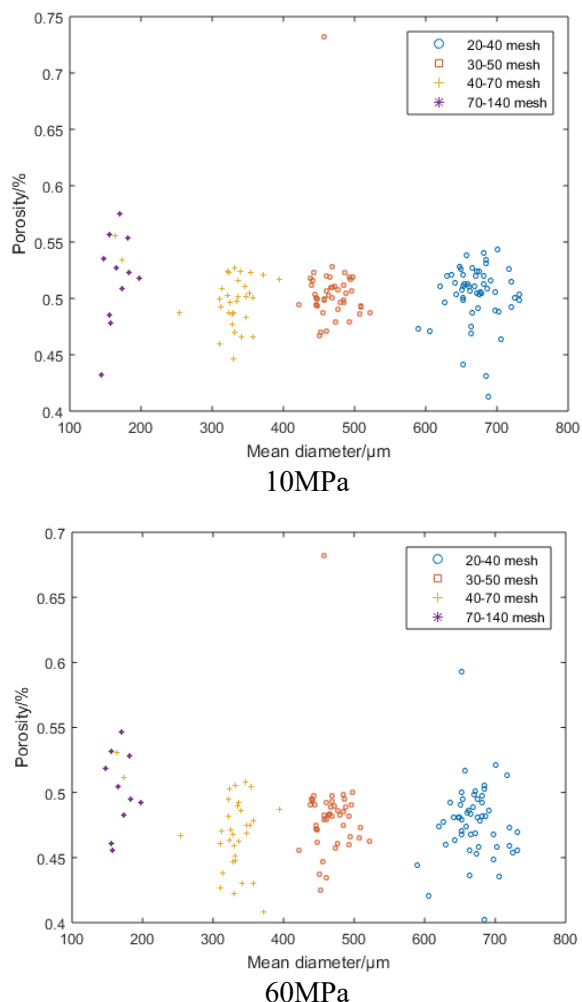

Fig.3. Relationship between mean diameter and porosity in ceramic.

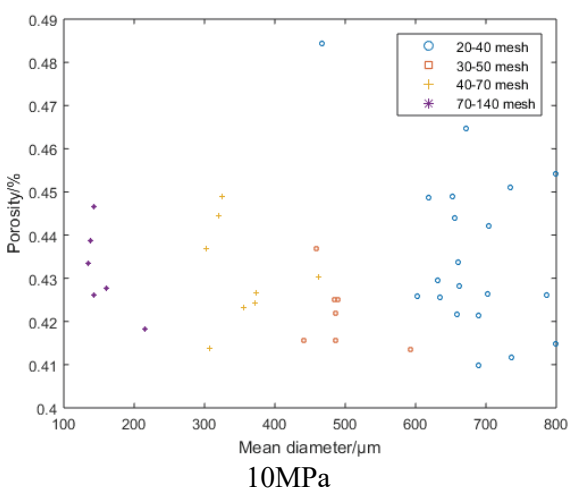

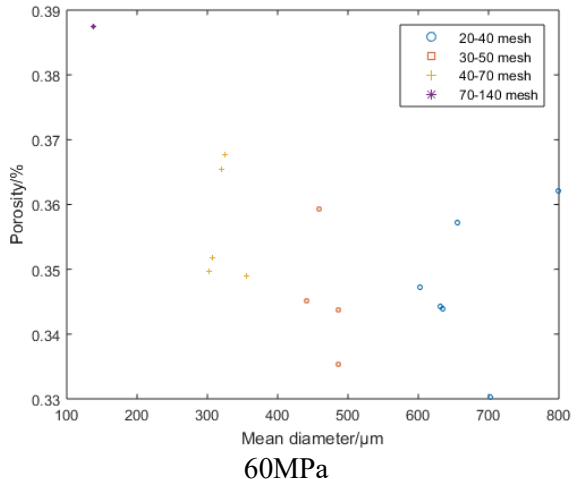

Fig.4. Relationship between mean diameter and porosity in sand.

\subsection{Porosity and conductivity analysis}

The experimental test results are shown in Figure 5 and 6 . The conductivity of the proppant-packs as a function of its porosity. The conductivity of the samples decreases with decreasing porosity. The conductivity is directly related to its particle size and porosity. Given the porosity, the smaller the particle size, the smaller the conductivity. Due to the low closed stress, the porosity data of 20/40 mesh sand is scattered, which is slightly different from the above rules.
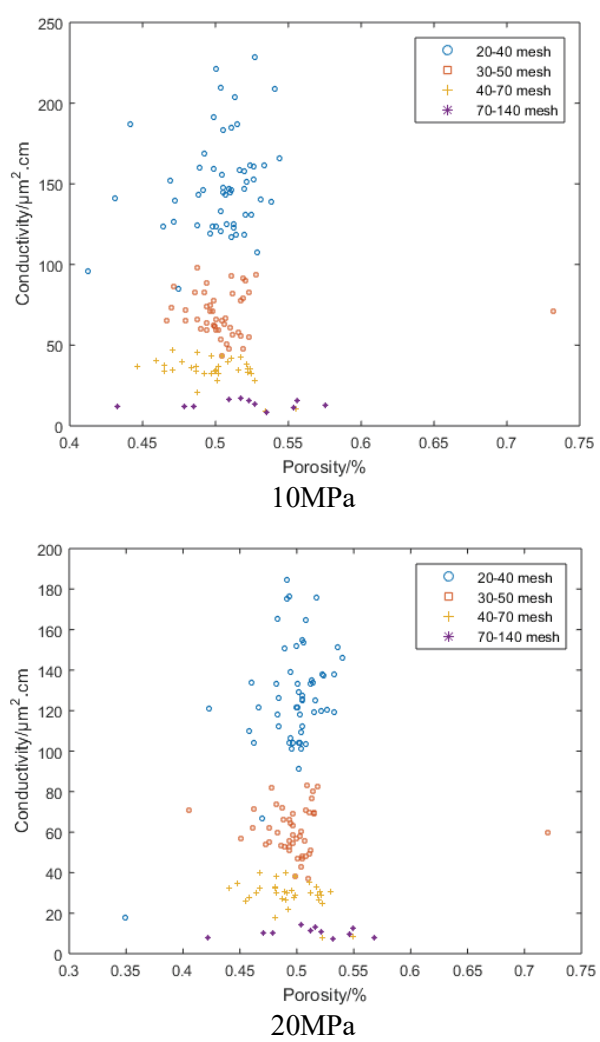

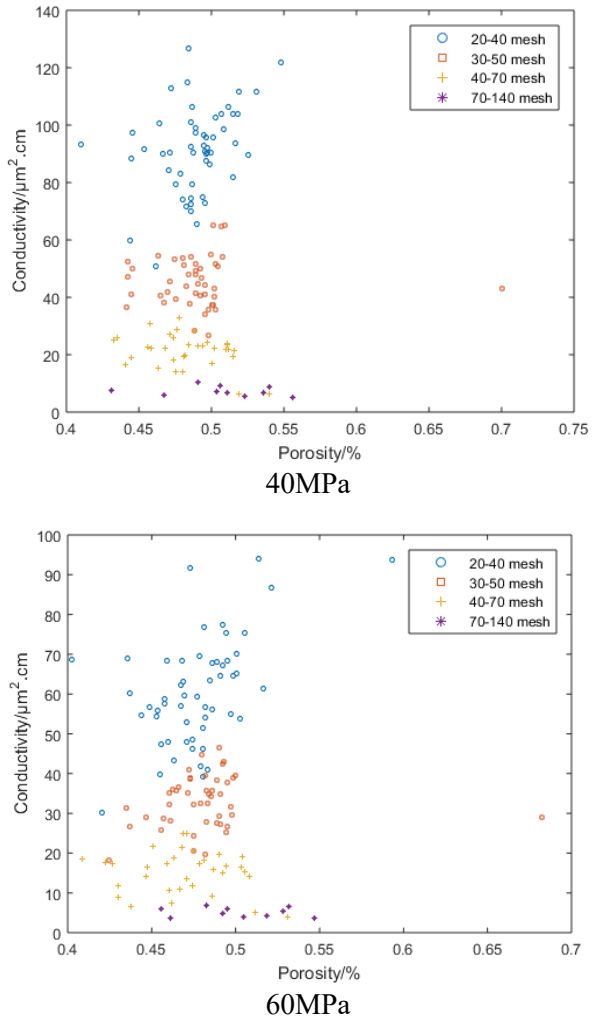

Fig.5. Relationship between porosity and the conductivity in Ceramic.
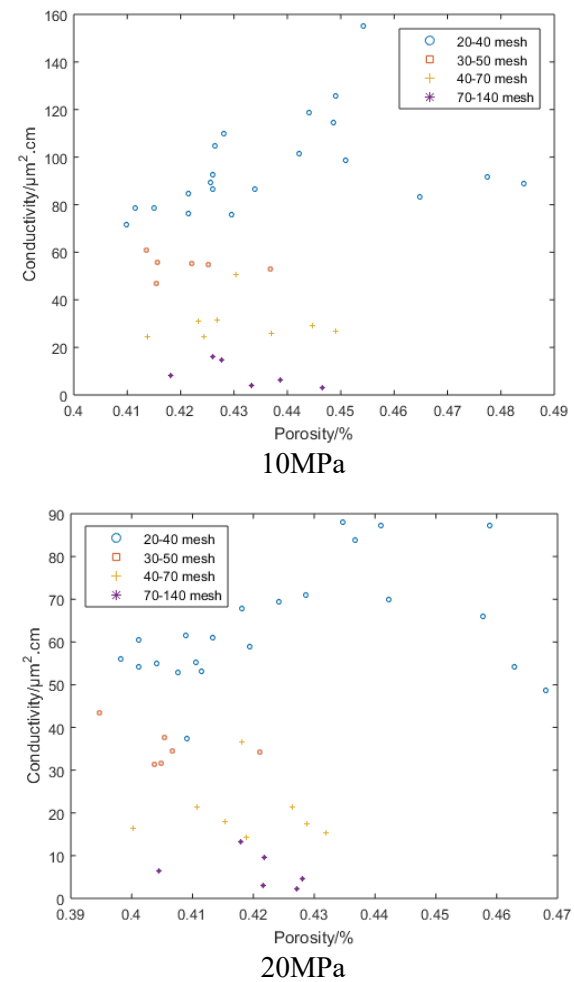
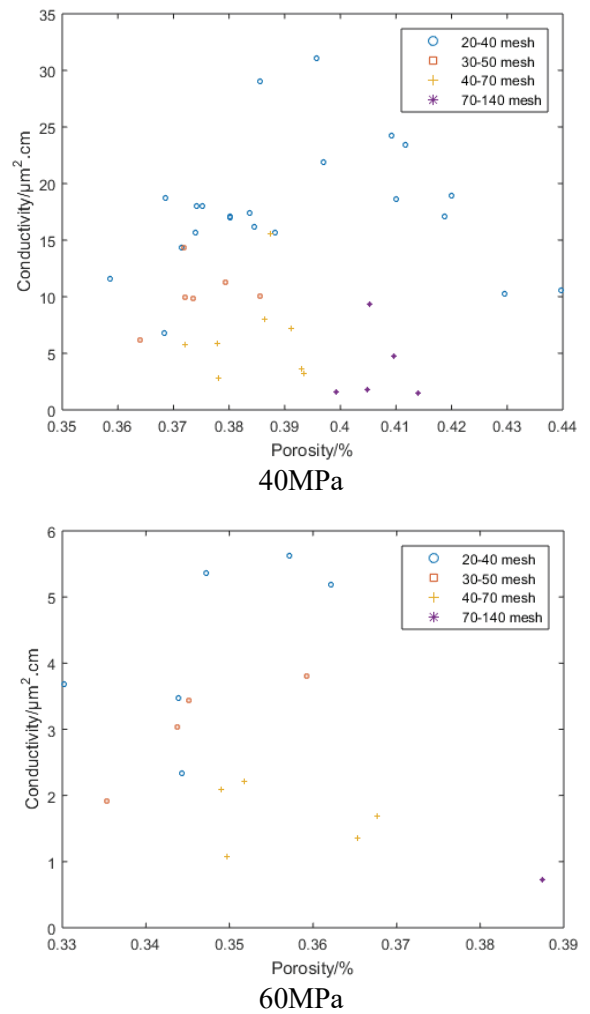

Fig.6. Relationship between porosity and conductivity in sand.

\section{Conclusion}

The proposed conductivity prediction modeling provides a useful alternative to the current theoretical or experimental portfolios. The optimization of proppant parameters could be finished in a more efficient and economical way without carrying out massive experiments.

The conductivity-porosity relationships are nonlinear. The conductivity is most sensitive to mean grain size, followed by closed stress, and then sorting. Larger median diameter always correlates to higher conductivity at low stress. Loss of conductivity with stress is more severe for large particles sands than small particles. The binomial method can be used to calculate the conductivity of different types and mesh proppants, which is shown to fit conductivity-mean diameter data successfully.

The research is of guiding significance to choose the proper size distribution proppants in hydraulic fracturing. Meanwhile, the binomial method is a better predictor of proppant-packs conductivity based on particle size distribution.

\section{References}

1. F. Zhang, H. Zhu, H. Zhou, J. Guo, B. Huang. Discrete-Element-Method/Computational-Fluid-

Dynamics Coupling Simulation of Proppant Embedment and Fracture Conductivity After 
Hydraulic Fracturing. SPE Journal.,4: 632-644 (2017).

2. R. J. Duenckel, R. D. Barree, S. Drylie, L. G. O'Connell and K. L. Abney, M. W. Conway. Proppants-What 30 Years of Study Have Taught Us. SPE 187451 (2017).

3. R. D. Barree, J. L. Miskinmins, M. W. Conway, R. Duenckel. Generic Correlations for Proppant-Pack Conductivity. SPE 179135 (2016).

4. M.M Mollanouri Shamsi, Sh. Farhadi Nia, and K. Jessen, Conductivity of Proppant-Packs under Variable Stress Conditions: An Integrated 3D Discrete Element and Lattice Boltzman Method Approach. SPE 174046 (2015).

5. M. M. Mollanouri-Shamsi, F. Aminzadeh, and K. Jessen. Proppant Shape Effect on Dynamic Conductivity of a Fracture Filled with Proppant. SPE 190024 (2018).

6. N.M. Panda, L. Lake. Estimation of Single-Phase Permeability from Parameters of Particle-Size Distribution. AAPG Bulletin 78, 7:1028-1039 (1994).

7. A. Dong, W. Pan, H. Yang, Z. Gan. Laboratory Study on the Influence of Fracturing Proppant Performance on Conductivity. Tech. Super. Petr. Industry 33, 24 (2017). 